\title{
Formação histórica do movimento adventista ${ }^{1}$
}

\author{
JOSÉ JEREMIAS DE OLIVEIRA FILHO
}

\section{De seita a igreja}

$\mathrm{O}$ S ADVENTISTAS recobram sua história através de uma cronologia que a classifica segundo dois critérios de codificação: a apreensão progressiva das "verdades fundamentais", por pastores e leigos orientados por "missão" divinamente inspirada nos "testemunhos" da "mensageira da Igreja Remanescente" - e pelas várias etapas de crescimento da "obra", a expansão do movimento de um pequeno grupo à forma de organização centralizada de que hoje dispõem. Estes dois critérios de classificação emergem na representação dos teólogos adventistas através de duas categorias, a de missão e a de comissionamento, entendendo-se por missãa o caráter sagrado do contato com o divino, aspecto antecipador da ordem social em relação à qual se dará toda a legitimação simbólica dos procedimentos práticos rituais, desde que "requer um relacionamento pessoal para e com Jesus Cristo que deve ser estrito e inviolável" 2 . A confirmação de tal missão exige, igualmente, a confirmação "de certos poderes de autoridade para o desempenho e plenitude desses deveres específicos, principalmente a autoridade para falar e agir como representante de Cristo", o que vem a ser a comis$s \tilde{a} o^{3}$. A autoridade assim sacralizada, à parte do mundo, é considerada como "solene responsabilidade" e "privilégio".

A "história" desse privilégio como histórica à parte prende-se à própria origem simbólica do movimento, uma parcialidade do mito cristão.

A emergência da missão comissionada em que se constitui o adventismo como forma de associação ocorre no contexto dos movimentos messiânicos do século XIX originados nos Estados Unidos, movimentos "messiânicosmilenaristas" ${ }^{4}$. A característica básica desses movimentos era o seu inconformismo com as associações religiosas já estabelecidas em Igrejas, tais como a Metodista, a Episcopal, a Presbiteriana e, principalmente, a Católica, daí Henri Desroche assinalar-lhes algumas características gerais:

a) reividicavam certa primazia de iluminação interior e do Espírito Santo, predominando não apenas sobre a Tradição, mas também sobre as próprias Escrituras;

b) pregavam que a Revelação não poderia estar terminada e que, portanto, uma nova era, a era do Espírito, reclamava novos profetas e os forneceria;

c) propunham, finalmente, realizar a Igreja como um mundo dentro do mundo, e sua recusa de relações com os poderes estabelecidos tinha por corolários 
a obrigação, para a sua Igreja, de se transformar mais ou menos numa autarquia econômico-política ${ }^{5}$.

Originam-se inúmeras comunidades rurais messiânicas que, com a industrialização dos Estados Unidos tendem a desaparecer paulatinamente, muitas delas, entretanto, aumentam o número de seus adeptos, como os Shakers e os Mórmons ${ }^{6}$.

As Igrejas protestantes, no período de 1793 a 1840, ampliam intensivamente o número de missionários no estrangeiro, caminho que será seguido pelas seitas que se expandem, algumas das quais sobreviverão na forma de Igreja ${ }^{7}$. Nos Estados Unidos formam-se, em breve período, as seguintes sociedades missionárias:

1796 - New York Missionary Society (Composta de presbiterianos, batistas etc.).

1796 - Northern Missionary Society, N. Y.

1798 - Connecticut Missionary Society.

1799 - Massachusetts Missionary Society.

1801 - New Jersey Missionary Society.

1802 - Massachusetts Baptist Missionary Society.

1802 - Western Missionary Society.

1805 - Great American Missionary Awakening Begins, Mass ${ }^{8}$.

1810 - Congretional General Association.

1814 - Baptist Missionary Union.

1819 - Methodist Church Missionary Society.

1820 - Protestant Episcopal.

1832 - Dutch Reformed.

1837 - Presbyterian Board9 .

Paralelas a essa necessidade de expansão externa do protestantismo norteamericano, ocorreram, internamente, neste país, inúmeras associações, tendência notada por Weber em sua caracterização como "rigorosamente exclusivas e voluntárias" ${ }^{10}$, sociedades de vegetarianos, clubes os mais variados, sociedades para a divulgação da Bíblia e outras tantas. Weber assinala a adesão às seitas, as mais exclusivas associações, pela prova de "qualificação religiosa" expressa na conduta, característica comum às seitas puritanas. $\mathrm{O}$ caráter de associação voluntária que é, para Weber, base de sua clássica definição de seita, se contrapõe à igreja, desde que esta se apresenta organizada administrativamente com vistas à atribuição de salvação que se permite em termos de pertinência obrigatória do adepto, já por nascimento" ${ }^{11}$ Igreja e seita permanecem como dois "princípios estruturais" "2, o compulsório e o voluntário que, no adventismo, permanecem em todos os níveis da associação; o voluntário, entretanto, especificando-se às etapas de adesão e, com a adoção do modo de vida do grupo, pelos adeptos, assume o caráter compulsório, grau cada vez maior de condição de fidelidade organizacional 
e ideológica. Daí a emergência da igreja na seita, sem que esta perca muitas de suas características da etapa anterior, a continuidade da forma de associação sendo mantida pela legitimação simbólica que, no adventismo, embora não em paralelo estrito com as práticas sociais, se torna complexa da seguinte maneira: o universo simbólico estrutura-se e em sua formação gera as "explicações" das atividades subseqüentes da prática adventista até ao estabelecimento de um conjunto orgânico de "verdades fundamentais" que, em sua maior parte, são precedentes a qualquer organização dos adventistas e que culmina por volta da penúltima década do século XIX, o congresso ou Assembléia Geral de Mineápolis de 1888 , já o adventismo apresentando certa diversidade administrativa de progressiva centralização ${ }^{13}$. Segue-se outra etapa em que a sistematização de regras de prática ganha relativa autonomia organizacional, com o conseqüente esvaziamento da condição estritamente individual dos meios de salvação, a emergência de uma nova ética, conquanto se possa perceber uma estruturação das regras de prática cada vez mais intensa e relativamente autônoma por critérios de eficiência da "obra" comissionada; o caráter legitimador da missão persiste, já não ligado a ordenações específicas, mas a conjuntos de regras de prática legitimadas em abstrato cada vez mais, o que terá sua principal afirmação na centralização administrativa progressiva que se acentua na Assembléia Geral de 1901, que precede a expansão mundial do adventismo como sua condição, e da qual participa ativamente a personalidade carismática da Sra. White. O conjunto de regras se torna mais complexo, abstrato, e sua absorção, legitimada simbolicamente, se dá de forma seletiva cabendo à organização o estabelecimento dos critérios desta seletividade, em consultas ao "passado" da associação religiosa na confirmação de seu universo simbólico, atualizado em representações e categorias diversificadoras e homogeinizadoras dos adeptos, numa reclassificação organizacional que não corresponde diretamente às classificações simbólicas instituídas no decurso da formação adventista. Daí que a permanência da ordem hierárquica legitimada torna indispensável a continuidade nas representações que a associação religiosa faz de sua história, de onde decorre ser impossível supor o comissionamento para a obra sem o relacionamento "pessoal" com a missão em que se constitui o passado que se contempla e gera as estruturas.

Seita, como voluntário, e igreja, como compulsório, permanecem como princípios estruturais internos que se absorvem; assim como as relações entre o simbólico e as práticas tornadas rituais ou legitimadas simbolicamente, as crenças para ação tornam-se mais complexas, no sentido de seletivas, à medida que o conjunto de regras de práticas compulsórias resultantes das relações sociais organizadas e previstas são intensificadas pela expansão da "obra" comissionada. O adventismo assumirá o caráter, então, de igreja, o que não foi possível nem a Weber ${ }^{14}$ nem a Troeltsch ${ }^{15}$ observar, e que os levou a enfocar, embora em referências de passagem, ao adventismo, como seita, exclusivamente, o que vem sendo repetido com freqüência ${ }^{16}$. 
Pode-se ainda considerar o aspecto seita-igreja como dois momentos de um processo de formação inerente às formas de associação e suas representações do fenômeno religioso. Assim, Mauss menciona a seita como subgrupo, atribuindo-lhe duas propriedades redimensionadoras: 1) a seita como "fenômeno de uma extrema generalidade", sendo, em algumas regiões, o próprio modo de existência do fenômeno religioso, - o Budismo com suas dezoito seitas da tradição clássica, com referência ao que denomina Mauss de religião universal; ou, mesmo em religiões nacionais, como o Bramanismo dividido, após tempos antigos, em partidários do ritualismo (purvamimansa ou karmamimansa) e "gnósticos"(jnãnaminansa ou uttataramimansa) e no Judaísmo, já nos tempos de Cristo com duas seitas, a dos fariseus e a dos saduceus; 2) de outro lado, a seita não sendo apenas "um fenômeno normal da história das religiões", mas ainda "um fenômeno inicial", desde que "é sob a forma de seita que nascem as religiões" 17 . Reformar, manter a pureza da revelação primitiva, acrescer ou opor novos modos de atividade e representação considerados superiores ao da igreja de que se desprende, ocorre no início das religiões, pois o caráter abstrato do substrato convencional é extraído do conjunto de adeptos, sem que, entretanto, a vida religiosa "esteja repartida de uma maneira uniforme entre todos os indivíduos" o que dá na ocorrência de subgrupos, em toda religião, "um certo ponto de vista e prática” de certa especificidade, os cultos e crenças parciais e de natureza diversa do conjunto de origem. As seitas pertencem à própria dinâmica da vida religiosa, sendo, como assinala Mauss, "o produto natural do funcionamento dos fenômenos religiosos"18.

O adventismo, desde o século XIX, colocará em discussão, com exclusão conseqüente, as numerosas "heresias", o grupo denominado de Carne Santa que aguardava a transladação; o panteísmo do Dr. J. H. Kellog; o Movimento Rowenita da Sra. Rowen (logo refutada por ser tida por falsa profetisa); a Vara do Pastor, criado na Califórnia, de onde Vitor T. Houterff dirigia severas críticas aos dirigentes adventistas defendendo uma salvação restrita a 144 mil que se organizaram com o nome de Adventistas Davidianos do Sétimo Dia, dissolvendo-se em 1962 ${ }^{19}$. No Brasil, as seitas dissidentes do adventismo são conhecidas pelos adeptos com o nome genérico de "reformistas", no momento com pequena persistência, a mais antiga tendo vindo da Alemanha, formada na época da Primeira Guerra Mundial por adventistas pacifistas, a Igreja Adventista do Sétimo Dia da Reforma, ou 2\% (devido à quantidade dos adeptos que originaram a dissidência), os pastores Lavrik e Kotzel, por divergências, separam-se em dois subgrupos, espalhando-se por São Paulo, Espírito Santo, Rio de Janeiro e outros Estados onde são de menor número. José Gomes Menezes, originado da seita anteriormente citada, após ter estudado no Colégio Adventista de São Paulo, fundou a Completa Reforma, hoje dissolvida. Outras seitas, menores ainda que as citadas, ocorreram em várias partes do país cuja principal clientela foi encontrada entre os adeptos do adventismo; assim, pode-se assinalar ainda, os 
wisheralistas, liderados por Wishel, centrados na década de 1930, em Itararé, São Paulo, com pequenos grupos em Curitiba atualmente (visavam a uma liberalização de costumes, permissão de bebidas, carne de porco etc., no que diferiam das demais seitas); na zona da baixada fluminense, em Xerém, forma-se a Igreja Adventista Brasileira, dirigida pelo ex-pastor Pedro Luiz de Souza, da Igreja Adventista do Sétimo Dia, com pequeno número de adeptos; finalmente, os Adventistas da Promessa, do Pastor Itamar; todos estes subgrupos tendo limitada duração ou restrita expansão, chegando a serem reabsorvidos após várias crises locais.

A origem do movimento adventista, como seita, apresenta-se, na primeira metade do século XIX, nos Estados Unidos, vinculada ao millenismo que empolga várias igrejas protestantes. Guilherme Miller, ainda que não pretendesse fundar dissidência, foi compondo por comparações entre textos bíblicos uma interpretação, a partir do livro de Daniel, que estabelece, através de um "cálculo" profético, uma cronologia que conjuga a história profana com a história sagrada, visando a interpretar a profecia das "duas mil e trezentas tardes e manhãs", o que levou a sucessivas marcações de datas para a volta do Messias, surgindo, assim, uma corrente numerosa de adventistas. O millenismo empolgou os Estados da Nova Inglaterra, atingindo Nova York, Filadélfia, Ohio, Michigan, e chegando, igualmente até o Canadá. Os futuros pioneiros da Igreja Adventista do Sétimo Dia, em grande parte, assistem a sermões de Miller; mais tarde, iriam efetuar correções em suas interpretações e ampliar o alcance da ênfase profética, representando, paulatinamente, uma cronologia mais rica, para a qual convergem inúmeras profecias, e que visa a periodizar o profano e o sagrado, em momentos que se sucedem com atributos específicos através dos quais chega-se ao "tempo do fim", tempo que corresponde a várias interpretações da divindade na história humana e comissionamentos que, pela ação, a tornam caminho de salvaçã $0^{20}$.

Várias profecias, como a dos sete cavalos, a dos sete selos, a das sete trombetas e a das sete igrejas, correspondem a períodos da história dos cristãos, as apostasias e a permanência da fé. O sonho de Nabucodonosor descrito e relatado pelo profeta Daniel, "a cabeça daquela estátua era de ouro fino; o seu peito e os seus braços de prata; o seu ventre e as suas coxas de cobre; as pernas de ferro; os seus pés em parte de ferro e em parte de barro" quando "uma pedra cortada sem mão" despedaça a estátua" ${ }^{21}$, é interpretado como uma sucessão de impérios, respectivamente, Babilônia, Medo-Pérsia, Grécia, Roma e os dez reinos em que o Império Romano foi dividido; a pedra que derruba a estátua sendo o reino indestrutível do Messias.

A cronologia, representada, assumirá especificidade na chamada "profecia das duas mil e trezentas tardes e manhãs" 22 , o mito de origem do adventismo, quando, a partir da ordem de reconstrução de Jerusalém pelos judeus, por Artaxerxes, o rei da Pérsia, no outono de 247 a.C., interpretando-se tarde e manhã como um ano, chegam-se a classificar vários períodos, até, finalmente, o ano de 1844, quando o "santuário será purificado". Ellen H. White, a profetisa do 
adventismo, resume a profecia, "conforme a luz que recebeu": tomando-se o outono de 457 como ponto de partida, e sessenta e nove semanas, conforme a profecia, os primeiros 483 anos dos dois mil e trezentos, deviam estender-se até o Messias, o Ungido; e o batismo e a unção de Cristo, pelo Espírito Santo, no ano de 27 da nossa era, cumpriu exatamente esta especificação. No meio da septuagésima semana o Messias deveria ser tirado. Três anos e meio depois de Seu batismo, na primavera do ano 31, Cristo foi crucificado. As setenta semanas, ou 490 anos, deveriam pertencer especialmente aos judeus. Ao expirar este período, a nação selou sua rejeição de Cristo, pela perseguição de Seus discípulos, e, no ano 34, os apóstolos voltaram-se para os gentios. Havendo terminado os primeiros 490 anos dos dois mil e trezentos, restavam, ainda, 1.810 anos. Contando-se desde o ano 34 de nossa era, 1.810 anos se estenderiam até 1844. "Então", disse o anjo, "o santuário será purificado". Todas as especificações precedentes da profecia se cumpriram inquestionavelmente, no tempo designado ${ }^{23}$.

Miller, entendendo a "purificação" como volta do Messias e, muitos outros pregadores igualmente, marcou data para o evento. Após muitas retificações, as comunidades adventistas aguardaram o Messias para 22 de outubro de 1844.

A não ocorrência da profecia ficou sendo chamada de "o grande desapontamento" pelos adventistas. Embora muitos abandonassem a doutrina do advento, permaneceu um pequeno número de adeptos do adventismo que efetuou sob a confirmação de Ellen Harmon, que passara a "receber visões" - por ela mesma considerada testemunhos -, uma retomada do universo simbólico, ainda disperso, mas que viria a se tornar nas "verdades fundamentais" da futura Igreja Adventista do Sétimo Dia, entre as quais constam as doutrinas do santuário, da guarda do sábado ${ }^{24}$, da mortalidade da alma e a reforma de saúde, como as principais.

Os "remanescentes" do adventismo millerista passaram a concentrar suas atenções na doutrina do santuário, a explicação para "o grande desapontamento de 1844". O santuário da profecia figura-se como idêntico ao tabernáculo construído por Moisés quando o povo de Israel vagava pelo deserto: um pátio exterior, os ofícios sendo realizados nos dois compartimentos, o "santo" e o "santíssimo". O segundo destes compartimentos era um local todo especial, pois ali, após oficiar no "santo", penetrava uma vez ao ano o Sumo Sacerdote e efetuava "uma obra especial de expiação" 25 . O santuário celestial equivale, agora, à existência do "novo concerto", e, em 1844, Cristo ultrapassa as cortinas do primeiro para o segundo compartimento, o dia da expiação, iniciando um período denominado de "tempo do fim", quando ocorre o início do preparo da vinda do Messias. Neste período, equivalente à última Igreja das profecias, a de Laodicéa, ao último cavalo, trombeta e selo, dá-se o início do "juízo investigativo", inicialmente dos mortos; a vinda do Messias ocorrendo quando do término do "juízo dos vivos" e da divulgação da mensagem de sua vinda, no que urge a missão tornar-se comissionada, transforma-se em atividade de proselitismo com o concurso e a responsabilidade dos adeptos, a "obra". 
À representação da origem do adventismo corresponde uma cronologia relativa ao período de tempo de fins do século XVIII ao século XIX e aos nossos dias, a doutrina das três mensagens angélicas. No Apocalipse, a volta do Messias é precedida por três anjos que, voando pelo meio dos céus, proclamam as suas mensagens: o primeiro anjo anuncia que "vinda é a hora do seu juízo" 26 , "adorai Aquele que fez os céus e a terra", interpretada como prenúncio do interesse pela volta do Messias despertado no que resultou nos adventistas, como os milleristas, não organizados em Igreja; a segunda mensagem Angélica, ("Caiu, caiu Babilônia [...]"), equivale à apostasia das igrejas que, não aceitando a mensagem adventista, terminam por expulsar, em massa os que nela criam; e a terceira mensagem, que se efetiva após 1844, menciona os que têm o "selo", "os mandamentos de Deus", com ênfase especial na guarda do sábado.

No verão de 1848 ocorreram várias “Conferências Sabáticas”em lugares da Nova Inglaterra, delas participando Hiran Edson, da parte ocidental de Nova York, que iniciara a elaboração da doutrina do santuário; José Bates, do sul da Nova Inglaterra, pioneiro no ensino do descanso no sábado; e Ellen Harmon (mais tarde White), do norte da Nova Inglaterra e que recebera o "dom da profecia”. As visões de Ellen aglutinarão os adeptos, orientando todos os passos para a formação do universo simbólico adventista. Dando às suas declarações escritas e orais o caráter de "testemunho", vem a ser chamada de "mensageira da igreja remanescente".

Ellen White, quando casada com James White, um dos futuros dirigentes da organização, considerando as inúmeras comunidades dispersas que se opunham a qualquer vínculo que não fosse doutrinário, escreveu, em 1859:

Há ordem no Céu, e Deus Se compraz com os esforços de Seu povo para procurar levar avante Sua obra na Terra com um sistema de ordem. Vi que deve haver ordem na igreja de Deus e que se necessita de sistema para levar, adiante, com êxito, a última mensagem de misericórdia ao mundo ${ }^{27}$.

A obra é uma categoria entendida pelos membros de duas maneiras, que foram "coletadas" em várias comunidades observadas pelo investigador. Aparece na representação dos agentes em termos de ordenação divina em que consiste a "obra de pregação do evangelho", "a prática cristã que ensina ao mundo a verdade", tarefa de todos os adeptos. Outro uso consiste no seu significado de organização, modo freqüente como os pastores consagrados e não consagrados e funcionários de dedicação plena à administração chamam de obreiros "os que trabalham na obra", na organização adventista. Na citação acima efetuada vê-se a categoria sendo utilizada em acepção comum aos dois empregos, o que igualmente foi observado pelo investigador na representação que da igreja faz exclusivamente o leigo. Ao passado da igreja como o "início da obra de Deus" se referem os pastores inúmeras vezes.

A organização da forma de associação comissionada somente foi efetivar-se com a centralização burocrática em 1901. A forma da estrutura atual da organi- 
zação será descrita em outro capítulo. A Sra. White, testemunhando para as comunidades, com aceitação crescente, forneceu-lhes as bases da missão comissionada, a autoridade e os deveres específicos que o "espírito de profecia" exige destas comunidades.

Não havendo nem registro dos membros, as comunidades religiosas adventistas tomaram algumas medidas, pois já não bastava, com o crescimento do número de adeptos, que os nomes dos recém-batizados constassem apenas no "livro da vida" junto ao Senhor ${ }^{28}$. Em 1851, um grupo de Washington resolve escolher diáconos, para garantir a celebração dos rituais na ausência do pastor. Dois ou mais pastores proeminentes passaram, em vários lugares, a emitir credenciais para os pregadores; a ordenação dos pastores seria uma prática somente adotada mais tarde. As assembléias regionais sucederam-se e James White sugeriu a unificação sistemática dos crentes, no congresso de Michigan (Battle Creek) de 1859, o que se efetivou no ano seguinte. Os crentes de Parkville, Michigan, ainda sem nome definido, registraram-se. Em 1861, surgiu a Associação de Michigan, outros Estados organizando as suas e, mais tarde, em 1863, sendo criada a Associação Geral em Battle Creek, em congresso a que acorreram delegados de diversas Associações de igrejas, com a ausência da de Vermont; elege-se uma comissão presidida pelo Sr. Byington e formula-se uma constituição. Isto não significava, ainda, uma centralização, pois as atribuições da Conferência Geral respeitavam a grande autonomia das Associações, sem funções claramente delimitadas em muitos dos setores em que os grupos locais acabaram por se especializar.

Um grave problema com que se defrontou a Associação Geral foi o da manutenção dos pastores, em 1878 sendo, finalmente, elaborado o plano de dízimos e ofertas, o que permitiu a profissionalização de grande número de pastores em tempo exclusivo. Os dízimos e as ofertas são considerados pelos adventistas como devolução ao Senhor, nas palavras de Ellen White, como lembrança de

que todas as coisas lhe pertencem. [...] Isto não é uma solicitação humana; é uma das ordenanças de Deus, pela qual Sua obra deve ser mantida e realizada neste mundo... Ninguém pode eximir-se do pagamento do dízimo e das ofertas ao Senhor ${ }^{29}$.

As Associações locais coordenadas na Associação ou Conferência Geral (entre os adeptos é comum a segunda acepção) não compreendiam a centralização de todas as atividades dos Adventistas do Sétimo Dia, pois desenvolveram-se, igualmente inúmeras organizações independentes que passaram a se especializar em determinadas atividades das congregações laicas ${ }^{30}$.

Em 1848, antes do início de uma conferência em Massachusetts, quando em oração, Ellen White recebeu uma "visão" que foi, de imediato, transmitida a seu marido:

você deve começar a imprimir um jornalzinho e enviá-lo ao povo. Seja ele pequeno a princípio; mas, à medida que o povo ler, enviará recursos para a 
impressão, o que o fará bem-sucedido desde o começo. Desse pequeno começo, foi-me mostrado, ele será como correntes de luz que irão em redor do mundo ${ }^{31}$.

Em 1849, James White iniciou a publicação do jornal The Present Truth, onde sua mulher publicará constantes artigos dirigidos às congregações. Posteriormente, surge o que seria o órgão oficial dos adventistas, The Advent Review and Sabbath Herald, que ficou conhecida, pelos membros, como Review and Herald, publicado a partir de 1861, inicialmente em Rochester e, mais tarde, deslocando-se a editora do mesmo nome para Battle Creek em Michigan, onde foi centralizado o adventismo. No cabeçalho de Review and Herald um trecho da mensagem do terceiro anjo "aqui está a paciência dos santos: aqui estão os que guardam os mandamentos de Deus e a fé de Jesus". Não consta nome algum no cabeçalho e as matérias são assinadas. Organizada a Review, outras editoras adventistas surgem: a Pacific Publishing Association, em Oakland, Califórnia; já em 1901, a Southern Publishing Association, no sul. E multiplicaram-se as edições e editoras com administrações independentes da Associação Geral, em 1860, com dezessete assalariados, editando dois periódicos, até a constituição do Departamento de Publicações, que chegara em 1970 a 2.379 assalariados, 279 publicações e 46 casa publicadoras.

Surgiram, com o nascimento da "obra", ainda outras organizações independentes da Associação Geral: a Associação Internacional de Liberdade Religiosa, a Junta Administrativa das Missões Estrangeiras, a Associação Internacional Médico-Missionária e de Beneficência e a Associação Internacional da Escola Sabatina. Esta última originou-se por iniciativa de James White, que anunciou pela Review a revista mensal Youth's Instructor, editada a partir de 1952. Em Rochester e Bridge, Nova York, surgiram dois grupos de pessoas que se dispuseram a estudar as lições bíblicas da revista, as Escolas Sabatinas, mais tarde incorporadas ao ritual da igreja. Após a escola-modelo de Battle Creek ter surgido, um de seus dirigentes sugeriu a criação de uma associação que englobasse as Escolas Sabatinas em cada Estado, com objetivo de consultas mútuas; sugestão levada a efeito na Califórnia e em Michigan, após o que, o plano generalizou-se. Essas associações estaduais vieram a formar a Associação Internacional das Escolas Sabatinas, que chegaram a financiar, diretamente, o proselitismo no estrangeiro. A participação na Escola Sabatina não tem, como pré-requisito, o batismo na Igreja e a classificação de membro da Escola Sabatina indica esta característica.

Os ensinos primário, secundário e, mais tarde, o superior, surgiram, a partir de 1874, em Battle Creek. De início com suas administrações totalmente isoladas, até a reorganização de 1901. Ellen White, nos livros Educação e Conselhos aos pais e professores, refere-se, continuamente, à necessidade de substituir o que denomina de "ensino mundano" da juventude adventista, pelo ensino sob orientação da igreja: "Seja a escola regida de acordo com as normas das antigas escolas dos profetas, achando-se a Palavra de Deus no fundamento de toda a educação 
dada" 32 . O Sr. McLearn, diretor do Colégio de Battle Creek, não preenchendo a finalidade de preparar "obreiros", em desrespeito às deliberações do "Espírito da Profecia", foi convidado a demitir-se; não concordando, enfrentou a denominação, que fechou o colégio por um ano. Mesmo com tal demonstração de autoridade, os educandários adventistas continuarão, por muitos anos, desligados de um controle centralizador.

Ellen White, voltando da Austrália, onde residiu algum tempo em atividades missionárias, teve atuação marcante em duas Assembléias: a de 1888 e a de 1901, dois momentos da história do adventismo. Na Assembléia de 1888 ocorreu uma clivagem doutrinária entre os adventistas, em torno da questão básica dos critérios de salvação. Tomando a Bíblia como "regra de fé e de prática", como se expressou James White, e confirmados pelos "testemunhos" de Ellen, as principais doutrinas adventistas - a Tríplice Mensagem, o Sábado, o Santuário, o Espírito de Profecia (nome dado aos "testemunhos" de Ellen), a Imortalidade Condicional -, estabeleceram-se durante a década iniciada em $1844^{33}$. Os millenistas que chegaram, segundo algumas estimativas, a cem mil pessoas, após o "grande desapontamento", ficaram reduzidos a alguns remanescentes dispersos, não chegando a constituir propriamente congregações. Expulsos de suas igrejas (Metodista, Batista, Metodista Episcopal etc.), apenas deram passos no sentido de se organizarem, poucos destes grupos, após 1851, orientados por uma "visão" de Ellen White do ano anterior, com medidas ainda parcamente centralizadoras: a concessão de credenciais a pregadores nas comunidades, assinadas inicialmente por James White e Joseph Bates; a diaconia instituída em Massachusetts, em 1854, de caráter estritamente local; a realização de constantes campanhas itinerantes de proselitismo montadas até em barracas, uma organização mais sistemática sendo efetuada por J. N. Andrews em Battle Creek numa comunidade que se tornaria modelo a partir de 1859. O próprio nome Adventista do Sétimo Dia somente foi adotado a partir de maio de 1861: a organização regional de Michigan surgindo no mesmo ano. Em 1863, foi organizada a Conferência Geral (nome de inspiração metodista) ${ }^{34}$. Antecedendo e acompanhando a estruturação das atividades práticas, legitimando-as e tornando-as rituais, o universo simbólico adventista, já prefigurado em suas bases na década mencionada, desenvolveu-se na integração das "verdades fundamentais" e outras, relativamente "menores", até o momento significativo em que se constituiu a Assembléia ou Conferência Geral de Minneapolis em 1888, onde um confronto ameaçou a unidade do movimento nas representações dos adeptos, surgindo, o que há muito se manifestava, uma clivagem quanto à questão dos meios de salvação, as doutrinas da justificação pela fé e pelas obras.

A própria composição de origem religiosa dos adeptos e pastores millenistas e sabatistas, na primeira metade do século XIX, tornava difícil a viabilidade de concentração doutrinária e organizacional, muitos destes participando, mais adiante, das comunidades adventistas. Assim, por filiação religiosa, temos os seguintes líderes: 
- Metodistas: Litch, Storrs, Robinson, Lindsey, Hale, Munger, Hutchinson, Cox, Smith, Stockman (e Ellen Harmon, mais tarde White);

- Presbiterianos - Congregacionalistas: Fitch; Hawley;

- Congregacionalistas: Jones, Bliss, Snow;

- da Igreja Cristã: Himes, Fleming, Bates, White, Cole;

- Protestantes Metodistas: Jacobs;

- Batistas: French, Preble, Bowles;

- Protestante Episcopal: Sabine;

- "Christian": Marsh, Cole.

Ainda outros pastores que eram luteranos e batistas do sétimo dia ${ }^{35}$.

A unidade do movimento adventista dependia de que o confronto entre a fé e a prática, como exclusivas, fosse solucionado: a tensão entre representações ritualizadas e míticas ameaçava o universo simbólico do adventismo e, conseqüentemente, seu status legitimador da ordem hierárquica em formação, ao nível da estruturação das crenças e da estruturação das práticas. Na Assembléia de 1888, os pastores Jones e Waggoner expuseram a doutrina da justificação pela fé e, os da facção oposta, a doutrina da justificação pelas obras nas palavras do Pastor Uriah Smith (este redator de Review and Herald, aquele, entre outras funções, com a redação da revista fundada por White na Califórnia, o Signs of Times - os periódicos básicos do adventismo de então), frente a setenta e oito delegados e muitos adeptos de várias partes. Após dias de debate, finalmente ocorreu a intervenção do "espírito de profecia" com admoestações a ambos os lados por não permitirem a "Deus a oportunidade de manifestar-se". Ellen White, desarmando as facções, enfatizou a "união em Cristo", embora afirmando a justificação pela fé e declarando, mais tarde, a importância das obras no caminho da salvação: "se bem que seja verdade que as boas obras não salvarão a uma única alma, é impossível que uma única alma seja salva sem as boas obras" ${ }^{36}$. Assim, a "justificação pela fé" torna-se uma "experiência, não uma teoria abstrata", tendo o encontro de Minneapolis como conseqüência ao "reavivamento e à restauração da primeira verdade e provisionamento da Cristandade - justificação e santificação". "recepção e transformação" em Cristo ${ }^{37}$. Às intervenções do "espírito de profecia" seguiram-se campanhas de "reavivamento", com o conseqüente desenvolvimento das atividades organizacionais, salvaguardada a legitimação do universo simbólico adventista e completada a sua estruturação.

A “obra” comissionada encontrava-se em apenas dois níveis administrativos, as Associações Locais e a Conferência Geral, esta com três homens compondo a comissão dirigente e, ainda as várias organizações independentes, mencionadas anteriormente, não sujeitas a autoridade centralizadora. A Sra. White já se referira, em seu artigo "Organização" 38 , à necessidade da associação dos adeptos em congregações organizadas, e, mais adiante, em apelo à ação que deveria caracterizar os adventistas (antes da publicação na mesma fonte, conforme se consta- 
tou consultando as publicações da época, de dez artigos sobre o tema da "Santificação", de janeiro a maio de 1881) expressando-se:

O tempo é curto e nossas forças devem ser organizadas para um trabalho maior. Necessita-se de trabalhadores que compreendam a grandeza da obra e que se engajem nela não pelas recompensas que recebam, mas pela realização da proximidade do fim. O tempo exige maior eficiência e a mais profunda consagração. [...] Estou tão convicta disso que clamo a Deus: envie-nos mensageiros com o senso pleno de sua responsabilidade, mensageiros em cujos corações a auto-idolatria, na qual reside o fundamento de todo pecado, tenha sido crucificada ${ }^{39}$.

A Assembléia Geral de 1901 efetuou a centralização definitiva da administração adventista, de todos os setores desenvolvidos até então, paralelamente; para Ellen "uma reorganização" necessária apoiada pelos pastores Haskell, Prescott, Waggoner, White etc., sendo aprovada a proposta de criação de uma “comissão de conselhos" na reunião do tabernáculo de Battle Creek. A comissão de setenta e cinco membros, presidida pelo Pastor Daniells, dividida em subcomissões, apresentou relatórios de seus trabalhos à assembléia. Ficaria assim o "campo" dividido em Associações-Uniões e Missões Uniões, formadas internamente por associações ou missões locais, estas compostas pelas congregações, respondendo as unidades administrativas denominadas de uniões à Associação Geral. Todas as organizações paralelas anteriormente criadas e algumas que surgiriam no futuro (como as associações de juventude, os Missionários Voluntários), passaram a formar os departamentos da Associação Geral. A Comissão Administrativa da referida Associação ampliada de treze membros para 25, "nenhum deles podendo ter interesses comerciais que se interpusessem entre eles e a obra" ${ }^{40}$. Os presidentes das associações-uniões participariam também da referida Comissão. O pastor Daniells foi eleito presidente da Associação Geral, ocupando, sucessivamente, o cargo de 1903 a 1922. Transferiu-se a sede do adventismo, por aconselhamento de Ellen White, por “visão", para Washington, Takoma Park, abandonando-se Battle Creek onde, segundo Ellen, estava a obra muito concentrada, devendo os crentes espalharem-se divulgando o advento em outras regiões. As relutâncias em seguir os conselhos do "espírito de profecia”, com respeito à tal transferência de sede cessam, após dois acidentes, os incêndios que destruíram o principal sanatório adventista e a editora Review and Herald - acontecimentos considerados como "lições" permitidas pela divindade ao seu povo.

Antes da Assembléia de 1901, a Sra. White recebeu uma de suas "visões" em que viu o "Eliseu rodeado por hostes angélicas em Dotã", considerando ela a Assembléia como o seu cumprimento, e se manifestando a respeito no último dia das reuniões: "Nunca me senti mais assombrada em minha vida que em face da direção que tomaram as coisas neste congresso. Esta obra não é nossa. Foi Deus que a realizou... Os anjos de Deus têm estado examinando esta congregação"4l. E acrescentou: 
Deus ordenou que os representantes de Sua igreja de todo o mundo, quando se reúnem em assembléia geral, estejam investidos de autoridade. Alguns estão em risco de incorrer no erro de conceder ao parecer e juízo de um homem, ou de um pequeno grupo de homens, a soma de autoridade e influência que Deus depositou em Sua Igreja, por meio do juízo e voz da assembléia geral reunida para formar planos em favor da prosperidade e adiantamento da Sua obra ${ }^{42}$.

Mais tarde, em 1913, surgiram as Divisões englobando as Uniões e completando a estrutura da organização em suas linhas mestras de atividade que, continuando a se desenvolver, resultaram em constante crescimento do número de “funcionários obreiros". De duas Uniões e 87 Associações e Missões, em 1900, até o final da década tem-se o aumento da organização adventista para 23 Uniões e 193 Associações e Missões, aumento que não ocorrerá, na mesma proporção, nos anos seguintes.

A importância da centralização de 1901 dota o adventismo de um aparelho burocrático centralizador eficiente e, pode-se dizer, assinala o "momento" a partir do qual torna-se impossível a inserção do adventismo na categoria de seita, embora minoritário, inclusive por concepção. Os adventistas são bastante céticos quanto à viabilidade de tornarem-se movimento majoritário em algum país, o que atribuem a necessidade de firmeza nos princípios".

Os adventistas, desde 1874, enviaram missionários ao estrangeiro, o que, juntamente com o número de obreiros "nacionais", levará ao aumento da porcentagem de funcionários da organização fora dos EUA, que, de 1,78\% do total de obreiros, em 1880, atinge, em 1950, a 77,26\%. As inversões da Conferência Geral fora dos EUA (apenas foi possível obter dados a partir de 1905) superam, de 1913-1914 em diante, a um milhão de dólares, em 1970 atingindo $\$ 49.735 .080,91$. Saliente-se que as verbas da C.G. serão obtidas pelas contribuições mundiais dos adeptos através de dízimos e ofertas especiais (a C.G. recebe o dízimo dos dízimos recolhidos pelas Uniões, estas, por sua vez, o dízimo dos dízimos recebidos pelas Associações). A Assembléia de 1901 marca uma nova fase de expansão, com o aumento, também, do número de adeptos fora dos Estados Unidos, de 586 adesões, em 1880, passando a 38.232 na década concluída em 1910; o número total de membros, em 1900, de 75.787, chegando a 104.526 e, em 1930, a 314.253, com os aumentos sucessivos posteriores do número de adeptos. Escandinávia, Dinamarca, Inglaterra, Rússia, Austrália, como o Pacífico Sul, África, Ásia e América Latina, foram atingidos pelo proselitismo adventista, com a formação, a partir de 1901, de várias Divisões, Uniões, Associações e Missões, hospitais, editoras e educandários. Dados referentes a adesões, no decorrer de 1972, na América Latina, foram fornecidos ao investigador pela União Este Brasileira dos Adventistas do Sétimo Dia (sediada em Niterói, Rio de Janeiro): na Divisão Sul-Americana verificam-se setenta adesões por dia com o surgimento de uma nova congregação por mês. 
O adventismo torna-se, assim, presente em inúmeros países através de um corpo de profissionais filiados à organização centralizadora. Fator importante na expansão do adventismo vem a ser a dedicação exclusiva do "obreiro" à causa da Igreja, com raras exceções (alguns médicos e advogados) que não incluem pastores ordenados, administradores, funcionários e "obreiros" não consagrados.

No Seventh-day Adventist Yearbook de 1972, com referência ao ano anterior, organizado pela Conferência Geral dos Adventistas do Sétimo Dia, foi possível coletar alguns dados relativos ao período atual da organização, em alguns setores importantes, como segue (resultados totais das divisões):

Membros batizados: 2.087.473

Igrejas organizadas: 16.629

Membros da Escola Sabatina: 2.603.860

Ministros ordenados na ativa: 7.422

Total de assalariados na ativa: 65.115

Escolas Primárias e Colégios Secundários: 4.557

Sanatórios e Hospitais: 139

Dispensários, Clínicas e Lanchas Médicas: 172

Médicos, dentistas, residentes e internos: 975

Enfermeiros: 4.653

Editoras: 48 - Número de línguas em que se edita: 266

A diferença entre aqueles denominados de membros da Escola Sabatina e os membros batizados, prende-se à caracterização dos primeiros como interessados e futuros adeptos, os que se encontram na etapa que precede ao batismo, o que nem sempre ocorre. Permanece, ainda, uma pequena margem de freqüentadores flutuantes não calculada, os que não chegam a se matricular na Escola Sabatina. De modo geral, são poucos os freqüentadores que não se decidem pelo abandono ou adesão por batismo. Permanecem membros da Escola Sabatina ainda aqueles de famílias adventistas que ainda não efetivaram a sua adesão. Todos os membros batizados são inscritos, sem exceção, na Escola Sabatina.

A expansão latino-americana do adventismo ocorreu a partir da segunda metade do século XIX, inicialmente através de publicações enviadas à Argentina por alguns parentes de imigrantes alemães, com a posterior vinda de "colportores" (os que vendem literatura denominacional), pastores e médicos que estabeleceram Missões, como, por exemplo, a do Pastor Stahl na Bolívia entre as populações incas do lago Titicaca. Com a criação de um colégio na Argentina, poucos anos após o pastor $\mathrm{F}$. H. Westphal ter criado a primeira igreja entre pequenos agricultores, difundiu-se o adventismo pelo Uruguai e pelo Brasil (onde a penetração foi realizada por intermédio de publicações como na Argentina). Esta foi a origem do que seria, mais tarde, a Divisão Sul-Americana, sediada em Montevidéu, em 1918, nos moldes estabelecidos pela Conferência Geral. 
De fins do Império à primeira República, estabeleceram-se núcleos adventistas em várias regiões do Brasil ${ }^{43}$. Inicialmente, com a chegada de exemplares de Stimme der Warheit ( $A$ voz da verdade) através do porto de Itajaí para alemães de Brusque; os periódicos editados em Battle Creek, Michigan, tornaram inúmeras famílias "interessadas" nas doutrinas adventistas, em Santa Catarina, sendo efetuados maiores contatos por correspondência com a editora e a Sociedade Internacional de Tratados dos Estados Unidos, que passaram a enviar novas publicações. A guarda do sábado, iniciada por Guilherme Belz, residente na colônia alemã de Gaspar Alto, após a leitura do comentário sobre Daniel de Urias Smith “Gedanken über das Buch Daniel”, também seguindo tal prática as famílias vizinhas Olm, Look e Thrun, deu seguimento a reuniões periódicas de um grupo de 22 pessoas. O colportor Albert B. Stauffer chegou ao Brasil em 1893, vindo, respectivamente, da Argentina e do Uruguai, com dois companheiros treinando, aqui, outro colportor, os três dedicando-se à venda de literatura denominacional entre alemães de Indaiatuba, Rio Claro, Piracicaba e outras localidades, resultando nos primeiros "interessados". Entre os livros vendidos salientou-se, então, Der Grosse Kampf ( O conflito dos séculos), de Ellen White. O colportor Stauffer iniciou, no adventismo, o casal Preuss pela venda de livros, como em outros lugares citados, batizando-os em 1897 - os primeiros adventistas do Rio Grande do Sul -, proprietários de um pequeno hotel na cidade de Taquari ${ }^{44}$.

Em 1894, chegou ao Brasil o Sr. W. H. Thurston, enviado pela organização para estabelecer, no Rio de Janeiro, um depósito visando a fornecer livros aos colportores; não assalariado pela organização, mantinha-se com as vendas. Os livros eram editados em inglês e alemão, o que acarretou grandes dificuldades à manutenção do colportor. Na mesma época, veio, para a América Latina, o pastor Westphal, que trabalhou entre alemães em Illinois, agora encarregado de dirigir o adventismo nesta parte do continente, residiu inicialmente na Argentina, vindo ao Brasil em 1895 para efetuar o batismo de alguns dos primeiros conversos, após ter sido informado pelo colportor Bachmeier que entrara em contato com "observadores do sábado" nas colônias alemãs de Santa Catarina, em Brusque e Gaspar alto. Nesta época, narram os adventistas, algumas pessoas foram batizadas no interior de São Paulo, em Piracicaba e Rio Claro, num total modesto de nove conversos. Em Joinville, trinta "almas" mostraram-se "interessadas na verdade"; mas seriam batizadas em outra ocasião. Em Brusque, o pastor Westphal encontrou oito conversos de duas famílias, Ludwig Look e Karl Thrun; em alguns dias, quinze batismos foram efetuados. A primeira congregação foi organizada em 1896, em Gaspar Alto; neste ano existiam, no país, cinco grupos adventistas efetuando reuniões periódicas, as Escolas Sabatinas: em Campos dos Quevedos e Taquari, no Rio Grande do Sul; em Joinville, Santa Catarina; e em Rio Claro, São Paulo. Por volta de 1900, aproximadamente, cem membros pertenciam à congregação formada em Gaspar Alto, onde surgira uma escola paroquial $^{45}$. 
Com o aumento do número de adeptos no Brasil, principalmente em Santa Catarina, Rio Grande do Sul, São Paulo, Rio de Janeiro e no Espírito Santo, a Associação ou Conferência Geral enviou dois pastores assalariados de seu quadro efetivo que chegaram em 1895 e no ano seguinte.

As edições em português das revistas O arauto da verdade (1900-1913), Sinais dos tempos (1913-1918) e de O Atalaia, foram inicialmente realizadas em Taquari, Rio Grande do Sul, em prelo manual, quando foi criada a Sociedade Internacional de Tratados do Brasil, igualmente patrocinando edições em alemão e português, respectivamente, das revistas Advent Arbeiter, Rundschau der Adventisten, a Revista trimestrale a Revista adventista; de livros como Oglorioso aparecimento de Cristo; e folhetos como Sucessos Preditos de História Universal, Cristo Nosso Salvador, Vereda de Cristo e Temperança cristã. Em poucos anos foi mudada a tipografia para São Bernardo, São Paulo, origem da atual Casa Publicadora Brasileira. O número de colportores teve acréscimo de quatro, em 1902, para 560, em 1962 e 1.500 em 1972; assim como as vendas, em 1906, de 6.723,80 cruzeiros atingem, em 1962, 401.757.198, 20 cruzeiros, 14.000,00 cruzeiros em 1972 (os colportores retêm cerca de 50\% de comissão, o que possibilita à grande maioria, a dos "efetivos", dedicação plena ao trabalho $)^{46}$.

A partir de 1896, surgiram inúmeras escolas e colégios adventistas no país. Gaspar Alto e Taquari tiveram as duas primeiras escolas e colégios adventistas no país. Gaspar Alto e Taquari tiveram as duas primeiras escolas missionárias que deveriam fornecer pessoal para o evangelismo e a administração. Em Santo Amaro, São Paulo, em 1915, foi criada a terceira escola missionária, o Seminário Adventista, com nomes posteriores de Colégio Adventista Brasileiro e Instituto Adventista de Ensino, cuja primeira turma graduou-se em 1922, composta de doze pessoas que iriam ocupar altos cargos na organização. Setenta por cento dos graduados de 1922 a 1962, em total de 855 estudantes, empregaram-se como "obreiros"; destes sendo duzentos pastores ordenados e 25 trabalham ou trabalharam para a Igreja Adventista no estrangeiro. Outros estabelecimentos de ensino surgiram no Rio Grande do Sul, em Taquara; Petrópolis, no Rio de Janeiro; em Cu-ritiba, Paraná; em Belém Maria, Pernambuco; Campinas, São Paulo; e Belém, no Pará.

Desde que iniciaram suas atividades no Brasil, a preocupação dos adventistas com serviços médicos, uma das principais maneiras de "pregação da Volta de Cristo" deu origem a inúmeros hospitais (como Silvestre, no Rio de Janeiro), Clínicas e ao atendimento às populações indígenas (desde 1928 os adventistas têm, por exemplo, contatos com os Carajás do Rio Araguaia) e às populações ribeirinhas do São Francisco, Araguaia e Amazonas através de lanchas médicomissionárias (neste último rio, o pastor L. B. Halliwell, em vinte e cinco anos, atendeu a 250 mil pessoas, a partir de 1931, deixando, na região, 22 igrejas, 56 Escolas Sabatinas, três mil adeptos batizados, um hospital e quinze escolas primárias), estas lanchas atendendo a, aproximadamente, 35 mil pessoas por ano, nos rios Amazonas e Parnaíba. 
Em 1920, o pastor Amador Reis foi ordenado, muitos brasileiros o seguiram e, com o correr do tempo, assumiram funções em todos os ramos da organização adventista. Atualmente, conforme pode ser constatado, são raros os estrangeiros que ainda permanecem na direção dos adventistas e, pertencendo ao quadro administrativo, há grande número de descendentes de imigrantes alemães do sul do país, sem que isto indique a existência de uma "igreja nacional", pois a administração, sediada no Brasil, participa da divisão do trabalho de salvação de "almas" conforme estabelecido pela Associação Geral.

A intensidade do proselitismo, uma característica das minorias religiosas protestantes, assumiu, no adventismo, conforme tem sido assinalado, formas cada vez mais complexas de atividades organizadas no Brasil não ocorrendo, entretanto, nenhuma organização paralela aos troncos centrais de decisão vinculados à estruturação mundial da Igreja Adventista. $\mathrm{O}$ único caso que pode ser registrado foi o da fundação criada pelo pastor S. L. Scofield, missionário entre as populações ribeirinhas das margens do rio São Francisco, em 1956 (trabalho que fora iniciado pelo pastor Paulo Seidl, dez anos antes), desligado da organização por pretender autonomia administrativa e, atualmente, em atividades na região.

Os adventistas denominam seu proselitismo de "trabalho de evangelização", o que caracteriza a própria existência da "obra" adventista, sendo a designação atribuída a uma categoria de pastores, os que "evangelizam" dedicando-se a "Séries de Conferências" etc. A "Colportagem” é considerada, também, um dos meios mais eficientes para se "ganhar almas". Os adventistas utilizam, ainda, o recurso do "evangelismo" pelos meios de comunicação de massa a partir de 1950, quando o pastor Roberto M. Rabello criou o programa radiofônico $A$ voz da profecia, seguindo o similar norte-americano, irradiado em português, alemão e japonês por 250 emissoras (aproximadamente trezentas em 1972), e de maior número no Estado de São Paulo (cerca de 75); 78 mil inscritos na Escola Rádio postal do programa, vinte mil tendo já completado o curso de doutrinas (os dados da fonte vão até 1962) ${ }^{47}$.

Como resultado destes "setores de evangelismo", as Conferências Públicas, a Colportagem, $A$ voz da profecia e muitos outros de menor importância efetuados por "obreiros" da empresa de salvação, a Igreja Adventista atingiu, na América Latina, segundo Seventh-day Adventist Yearbook de 1972 (com estatísticas referentes ao ano anterior), a 278.061 membros batizados e 1.059 igrejas; 163.924, no Brasil, distribuídos pela União Norte (20.706), União Este (51.675) e União Sul (91.543). O número de adesões ao adventismo, em 1972, atinge, aproximadamente, a vinte mil.

No Rio de Janeiro e no Rio Grande do Sul originou-se, em 1902, a administração adventista, com dois dirigentes locais, Spies e Graf. Depois, foi organizada a União Sul-Brasileira (1911), com três associações e três missões; em 1919, a União Este-Brasileira, com duas associações e três missões; por último, em 1936, a União Norte-Brasileira, composta de três missões. 
Quando o adventismo chegou ao Brasil, seu universo simbólico, legitimador das práticas sociais, já estava estruturado. A "missão comissionada" na forma de associação organizou-se de modo cada vez mais diversificado, o conjunto das regras de ação tornando-se mais complexo. As doutrinas legitimadoras, nas quais crêem, referem-se a uma "história", a do povo de Israel, com o qual Jeová efetuara o "Velho Concerto", povo que não cumprira sua missão comissionada com a rejeição de Cristo. Daí o "Novo Concerto", a passagem do Santo para o Santíssimo no "santuário celestial", o início do tempo do fim, a última igreja, o último cavalo, a última medida de tempo na cronologia da história à qual está designada a mensagem Angélica de Apocalipse 14, 16: “[...] o evangelho eterno para proclamar aos que habitam sobre a terra, e a toda nação, tribo e língua e povo". Instados pelo seu repertório de possibilidades cognitivas de ação, os adventistas representam o término de sua "missão comissionada" com o término do anunciamento da "mensagem" e sua organização tem por fim o que explicitam como simbolização e prática: “o objetivo desta Associação é anunciar a todas as nações o evangelho eterno de nosso Senhor e Salvador Jesus Cristo e os mandamentos de Deus" ${ }^{48}$. A União Este-Brasileira assim expressa o mesmo universo:

Esta Associação se propõe os seguintes objetivos:

a) pregar o Evangelho de Nosso Senhor Jesus Cristo a todos os habitantes de seu território, difundir o ensino religioso, intelectual, moral, cívico e princípios de saúde;

b) contribuir, dentro de suas possibilidades, por meio de suas instituições, para a assistência social e educacional gratuita, sem distinção de credo ou classe;

c) cooperar na pregação do Evangelho a todos os povos.

Parágrafo único - $\mathrm{O}$ cumprimento deste artigo será feito por meio de seus templos, instituições médicas, hospitalares, assistenciais, educacionais, lanchas-ambulatório, clínica-rodante, aviões-ambulância, serviço educacional lar e saúde, sociedades beneficentes e outras instrumentalidades apropriadas e lícitas para conseguir este desiderato ${ }^{49}$.

Os Estatutos da Associação Paulista delimitam as responsabilidades nacionais e internacionais do proselitismo como base de ação:

O fim a que se propõe esta Associação é difundir o Evangelho de Nosso Senhor e Salvador Jesus Cristo a todos os habitantes do seu respectivo território, e contribuir para a propagação da verdade evangélica entre todas as nações do mundo, por meio de igrejas, organizações, instituições médicas e de saúde, estabelecimentos de educação. Publicações, agências missionárias e outras instrumentalidades e métodos apropriados e lícitos para conseguir esse desiderato. Fica expressamente declarado, que esta Associação não visa a interesses nem lucros pessoais ou quaisquer outros, mas que todas as suas propriedades serão utilizadas e empregadas, no sentido de atingir o fim a que se propõ $\mathrm{e}^{50}$.

$\mathrm{O}$ ascetismo adventista configura-se, assim, como atividade cujo teor "energético" é dado pela "urgência da proclamação". A representação da sua "histó- 
ria" apresenta-se por uma relação cognitiva de três planos de referência: a representação da "história" de Israel aos cristãos (que Ellen White segue passo a passo em suas "visões" publicadas no "Conflito dos séculos"); a representação de sua origem no século XIX (conseqüência da "história" anterior) o que redundará na estruturação das "verdades fundamentais" até por volta de 1888, orientados pelos "testemunhos" de Ellen White; e o conjunto das regras de ação legitimadas pelas representações anteriores como sacralizadas e, deste modo, rituais que se caracterizam pela atrofia do cerimonial de culto e com a multiplicação das regras organizacionais à medida que se expande a "obra" comissionada.

"Usando no serviço de Deus a capacidade que ele lhes concedeu, a comissão que Cristo deu aos discípulos justamente antes de Sua ascensão é o grande alvará missionário de Seu reino" e "dando-o aos discípulos, fê-los o Salvador embaixadores Seus, e conferiu-lhes credenciais" 51 . Tanto os discípulos como seus sucessores recebem a comissão de estabelecer os alicerces da igreja, "Cristo lhes apresentou o mundo como seu campo de trabalho", pois "deviam ir a todo o mundo pregar o evangelho a toda criatura"; a "comissão dada aos discípulos é dada, também, a nós", então "todos sobre quem foram derramadas as bênçãos de Deus, devem corresponder por meio de serviço fiel" ${ }^{2}$. "Cristo tomou todas as providências para o prosseguimento da obra confiada aos discípulos, e assumiu, Ele próprio, a responsabilidade do êxito da mesma. Enquanto obedecessem à Sua palavra e com Ele trabalhassem em união, não poderiam fracassar. Ide a todas as nações, ordenou-lhes Ele" 53 .

O terceiro anjo afirmou duas qualificações do sujeito da "proclamação da mensagem": a primeira, a "guarda dos mandamentos de Deus", o decálogo de Moisés; a segunda, o conhecimento sagrado do "Testemunho de Jesus", definido por São João (Apocalipse 12) como o "espírito de profecia" ${ }^{4}$. Decorrem destas duas características a concepção que de si fazem os adventistas como "povo escolhido" para a "obra de proclamação" no "tempo do fim".

Na representação de sua história os adventistas vêem a realização das profecias indicadoras do "tempo do fim" como associadas à função da última igreja, um "povo" marcado pelo "selo" da "guarda" dos mandamentos e pelo Espírito de Profecia, não para substituir a Bíblia, mas para que "a humanidade melhor a pudesse compreender, e para orientar a vida cristã" ${ }^{" 55}$.

Nos primeiros tempos do adventismo, várias pessoas "receberam" "visões": Guilherme Foy por duas vezes, na terceira, desistiu da tarefa de contá-la e de ser "mensagerio"; o mesmo ocorrendo com Hanzen Foss, aquele, membro da comunidade batista de Boston, em 1842; este, moço adventista de Portland. Os casos foram interpretados pelos adventistas, posteriormente, como "rejeição do dom de profecia", atitude oposta à de Elle Harmon que, a partir de 22 de outubro de 1844, teve sua primeira "visão", narrada dias depois a um grupo de sessenta crentes de Portland, Maine. 


\section{Notas}

1 As exposições e análises subseqüentes terão por base a "história-para" segundo as representações adventistas. A partir daí poder-se á efetuar a exposição demonstrativa, esperando-se que as classificações e pontos de vista adotados pelo investigador não adulterem o material compulsado. Privilegiaram-se como fontes tanto a profetisa dos adventistas quanto depoimentos escritos de teólogos e pastores, além de dois livros-textos preparados pelo Departamento de Educação da Associação Geral, usados amplamente pelos adventistas para "reativar" a sua história na representação das novas gerações, e que serão citados oportunamente. Tal critério auxiliou na coleta de informações relevantes da história adventista.

2 Le Roy Edwin Froom, Movement of Destiny, Washington, Review and Herald Publishing Association, 1971, p. 630.

\section{Idem, ibidem.}

4 Maria Isaura Pereira de Queiroz, O messianismo no Brasil e no mundo, São Paulo, Dominus/Edusp, 1965, p. 92.

5 Idem, p. 93.

6 Idem, p. 95.

7 Considerado como uma das formas de "chamado" para a "obra do Senhor" pelos adventistas, o envio sistemático de missionários ao estrangeiro acarretará na emergência de organismos especificamente dedicados a este fim. Com respeito a esta atividade pelos adventistas serão fornecidas estatísticas mais adiante.

8 Le Roy Edwin Froom, op. cit., p. 52.

9 Idem, p. 54.

10 Max Weber, Les sectes protestantes et l'esprit du capitalisme, editado com L'ethique protestante et l'esprit du capitalisme. Trad. M. Jacques Chavy e rev. Por Louis Dumont e Éric de Dampierre, 2 $\underline{a}$ ed. rev., Paris, Librairie Plon, 1967, p. 267.

11 Idem, pp. 261-262 e 274.

12 Idem, p. 274.

13 História de Nossa Igreja, obra coletiva elaborada pelo Departamento de Educação da Associação Geral da Igreja Adventista do Sétimo Dia, trad. Odair Linhares e Isolina A. Waldvogel, São Paulo, Casa Publicadora Brasileira, pp. 247-251.

14 Max Weber, op. cit., p. 263.

15 Ernst Troeltsch, The Social Teaching of the Christian Churches, trad. Olive Wyon, London, Allen e Unwin, vol. 2, 1931, p. 725.

16 Henri Desroche, citado em Maria Isaura Pereira de Queiroz, op. cit., p. 96. Tal postura pode ser assinalada ainda em Bryan Wilson, Sociologia de las Sectas Religiosas, trad. Carlos Pascual, Madrid, Guadarrama, 1970, pp. 99-103.

17 Marcel Mauss, Oeuvres, 1. Les foctions sociales du sacré. Paris, Minuit, 1968, pp. 9798.

18 Idem, p. 99. 
19 História de nossa igreja (a ser referida daqui por diante como HNI), pp. 243-245.

20 Max, Weber, "Sociologia de la Religión”, em Economia y Sociedade, México, Fondo de Cultura Econômica, 1964, p. 420. Empregou-se aqui a expressão de Weber para indicar as possíveis influências de uma religião sobre as práticas sociais conforme o caminho de salvação.

21 Daniel 2, 32-34.

22 Daniel 9: especialmente os versículo 25-27. "Sabe e entende: desde a saída da ordem para restaurar e para edificar Jerusalém, até ao Messias, o Príncipe, sete semanas, e sessenta e duas semanas: as ruas e as tranqueiras se reedificarão, mas em tempos angustiosos". "E depois das sessenta e duas semanas será tirado o Messias, e não será mais [...] E ele firmará um concerto com muitos por uma semana: e na metade da semana fará cessar o sacrifício [...]". E em Daniel 8, 14: "Até duas mil e trezentas tardes e manhãs, e o santuário será purificado". Os adventistas terão um modo peculiar de interpretação comparativa das passagens bíblicas proféticas, o que evidenciará o seu universo simbólico, legitimador.

23 Ellen G. White, O conflito dos séculos, São Paulo, Casa Publicadora Brasileira, p. 444.

$24 \mathrm{Um}$ estudo recente sobre os aspectos da guarda do sábado na Igreja Adventista, o de Wagner Neves Rocha, O sábado e o tempo, Rio de Janeiro, Museu Nacional/ UFF, 1972.

25 Ellen G. White, op. cit., p. 453.

26 Apocalipse 14, 6-12. Salientando-se alguns trechos: "Eu vi outro anjo voar pelo meio do céu, e tinha o evangelho eterno, para proclamar aos que habitam sobre a terra, e a toda nação, e tribo, e língua, e povo. [...] Dizendo com grande voz: Temei a Deus, e dê-lhe glória; porque vinda é a hora de seu juízo. E adorai aquele que fez o céu, e a terra e o mar, e as fontes das águas. [...] E outro anjo seguiu dizendo: Caiu, caiu Babilônia, aquela grande cidade, que a todas as nações deu a beber do vinho da ira da sua prostituição. [...] E seguiu-os o terceiro anjo, dizendo com grande voz: Se alguém adorar a besta, e a sua imagem, e receber o sinal da sua testa ou na sua mão $[\ldots]$ também o tal beberá do vinho da ira de Deus $[. .$.$] Aqui está a$ paciência dos santos, aqui estão os que guardam os mandamentos de Deus e a fé de Jesus". Este último versículo tem uma variante de tradução utilizada pelos adventistas (na revisão da tradução Almeida): “[...] os que guardam os mandamentos e tem o testemunho de Jesus" (grifo meu) - e que comparam, interpretativamente, com outra passagem (Apocalipse 19, 10): “[...] porque o testemunho de Jesus é o espírito de profecia".

27 HNI, p. 226.

28 Idem, p. 358.

29 Ellen G. White, Testimonies to Ministers, p. 307, apud Manual da igreja, São Paulo, Casa Publicadora Brasileira, p. 181.

30 Max Weber, op. cit., p. 366 refere-se às congregações laicas como resultado da transformação dos círculos de simpatizantes desorganizados em instituição permanente, estabelecendo-se entre os discípulos "uma sociedade exclusivamente a serviço de fins religiosos". 
31 Testemunhas de Jesus, preparados por um grupo de professores escolhidos pelo Departamento de Educação da Associação Geral dos Adventistas do Sétimo Dia, São Paulo, Casa Publicadora Brasileira, trad. Isolina A. Waldvogel, p. 369 (citado daqui por diante como T. de J.).

32 Citado em T. de J., pp. 389-390.

33 Leroy Edwin Froom, op. cit., p. 142.

34 Idem, pp. 131-141.

35 Idem, p. 146.

36 Esta postura doutrinária terá importantes conseqüências para o movimento adventista.

37 Leroy Edwin Froom, op. cit., p. 268.

38 Publicado na Second Advent Review and Sabbath Herald, no 13 , de agosto de 1861.

39 Ellen G. White, Testemonies for the Church, California, Pacific Publishing Association, 1926, vol. 9 , p. 27

40 HNI, p. 257.

41 Citado em HNI, p. 258.

42 Idem, p. 259.

43 Gideon de Oliveira, "A penetração da mensagem adventista no Brasil", anexado à $H N I$, o único trabalho que foi possível encontrar referente ao Brasil, conquanto sintético. O autor possui uma coleção de documentos recolhidos para uma história da Igreja Adventista em elaboração. As revistas adventistas apenas trazem depoimentos esparsos, nem sempre coincidentes.

44 Leopoldo Preuss, "O começo da mensagem adventista no Brasil”, Revista Adventista, São Paulo, abr. 1963, p. 26.

45 Gideon de Oliveira, op. cit., pp. 311-313.

46 Idem. Os dados de 1972 foram fornecidos pelo Departamento de Colportagem da União Este Brasileira.

47 Idem, pp. 319-322.

48 Constituição e estatutos da Associação Geral dos Adventistas do Sétimo Dia, art. II, Divisão Sul-Americana, Montevideo, 1971.

49 Idem, art. 11.

50 Idem, art. III.

51 Ellen White, Testemunhos seletos, São Paulo, Casa Publicadora Brasileira, 1956, vol. III, p. 205.

52 Idem, pp. 206-207.

53 Idem, p. 208.

54 Renato Oberg, A igreja de Deus através da História, União Este Brasileira dos Adventistas do Sétimo Dia, Depatamento de Educação, mimeo., p. 10.

55 Idem, p. 11. 
RESUMO - PRETENDENDO-SE efetuar uma história compreensiva da Igreja Adventista do Sétimo Dia, segundo a representação dos adeptos da "obra" e da "mensagem", a formação da sua representação simbólica e as práticas organizacionais orientadas pela profetisa Ellen G. White, o artigo trata do surgimento, no millenismo, do movimento adventista que transformará a seita inicial em uma igreja estruturada burocraticamente, o "comissionamento" legitimado simbolicamente pela "missão". A presença dos Adventistas no Brasil entre o final do Império e início da Primeira República sustenta as mesmas características iniciais do movimento, embora, por sua vez, gere a inúmeras seitas.

ABSTRACT - HOPING to provide a comprehensive history of the Seventh-Day Adventist Church according to the representation of "work" and "message" by their adepts, the establishment of the Church's symbolic representation, and the organizational practices guided by prophetess Ellen G. White, this essay deals with the emergence, in Millenarianism, of the Adventist movement - which would transform the initial sect into a bureaucratically structured church, with its "commissioning" symbolically legitimized by the "mission". The presence of Adventists in Brazil between the end of the Empire and the beginning of the First Republic sustains the same initial characteristics of the movement, although it also generates numerous sects.

José Jeremias de Oliveira Filho é professor do Departamento de Sociologia da Faculdade de Filosofia, Letras e Ciências Humanas da Universidade de São Paulo (FFLCH-USP).

Este texto é a primeira parte do Capítulo l da Tese de Doutoramento do autor - $A$ Obra e a Mensagem: Representações simbólicas e organização burocrática na Igreja Adventista do Sétimo Dia -, apresentada ao Departamento de Sociologia da FFLCHUSP, em 1972, tendo como orientador o Prof. Dr. Luiz Pereira.

Texto recebido e aceito para publicação em 26 de agosto de 2004. 